\title{
If you build it, will they come? Not unless you make it so they want to!
}

\section{Thom Remington}

is the Digital Asset Manager for DuPont Safety \& Protection, which includes brands such as Corian ${ }^{\circledR}, \operatorname{Kevlar}^{\circledR}, \operatorname{Nomex}^{\circledR}$ and Tyvek ${ }^{\circledR}$. His background includes mental health work, sales, user support, technical writing and programming. DuPont is a science company based in Wilmington, Delaware, with research, manufacturing, marketing and sales offices worldwide. Prior to the implementation of this system, digital asset management in DuPont was fragmented; in most cases, there were collections of CDs somewhere, sometimes cataloged, but usually not. Accessibility was an issue as well, because there was very little communication across the company about what was available.

\section{Keywords: DAM implementation, workflow, change agent, training, metadata}

Abstract This paper discusses the differences between the digital asset management (DAM) system and the DAM processes, focusing on the inertia faced when we try to implement something new. A new system may be an improvement, but we have to help people to understand what's in it for them, which leads them to understand why they should learn to use it.

Journal of Digital Asset Management (2006) 2, 203-207. doi:10.1057/palgrave.dam.3650021

\section{INTRODUCTION}

You've built a marvelous new digital asset management (DAM) system, and now you're having a hard time getting people to use it. They just keep on doing what they've been doing. Welcome to the Wonderful World of Human Nature. You're not facing anything new. It's part of the way people are.

Consider this analogy. In marriage counseling, there's one paradigm that characterizes marriages according to a two-by-two matrix.

\begin{tabular}{lll}
\hline & Stable & Unstable \\
\hline Satisfactory & 1 & 2 \\
Unsatisfactory & 3 & 4 \\
\hline
\end{tabular}

Thom Remington Digital Asset Manager DuPont Safety \& Protection, CRP 721/2340, 4417 Lancaster Pike, Wilmington DE 19805 USA

Tel: +1 3029993666 ; Fax: + 13029992190 E-mail: thomas.

f.remington@usa.dupont. com
Thus, some marriages could be characterized as unstable but satisfactory (cell 2). One of the hardest to treat is the stable-unsatisfactory, found in cell 3. In this marriage, the partners are unhappy with each other and their relationship, but the prospect of change is more frightening than keeping things as they are. The stability of the relationship makes it harder to change, even though the couple may be miserable.
Trying to change work processes can be very similar. When we introduce a DAM system, whether it replaces an existing one or a nonsystem (CDs in desk drawers or something similar), users are going to have to change their habits. They're used to doing things a certain way, and, no matter how awful the current way is, it's the way they're comfortable with. Change is hard, even when it's for the better. Change is even harder if you're asking folks to get used to a different computer system and processes for dealing with assets. Not only that, but your new DAM is likely to change the rules for who gets to do what with assets. Some users will have no problem with the rules; others will find them too confining or inconvenient.

Of course, some users are going to latch onto the new system right away, but others are going to shy away from it; it's something new to learn, and they're already overloaded with other work. Besides, Jim is just down the hall, and he's got all the images I need on CDs in his credenza. And he doesn't make me remember yet another password and learn yet another computer system. 


\section{DIFFERENT THINKING STYLES}

It's no secret that different people view the world differently. I confess. I'm a toy guy. I like my toys, I like trying new stuff, and I love learning my way around new software applications. Most of the communications people I work with are very different in this regard. They look at the processes involved, the ways in which information and assets move throughout the organization and they see DAM very differently.

We could have faced a serious dilemma had we not really investigated the way we look at things and come to a mutual understanding. This was especially important for our training sessions, which were the first in-depth look that most users had with the system. Being the toolsand-toys guy, I had set out to show folks our spiffy new DAM system, all bright and shiny. What I hadn't taken into account was the fact that most of the folks in the organization were more interested in how the tool would help them than in all the bells and whistles.

Our first training session with the marketing communications professionals was a discussion of the capabilities of the tool itself. It was ineffective. The people attending the session found it hard to follow and left without having gained an adequate understanding of the processes or of the tool itself. The training lacked context. Without a process to provide that context, to show what the tool actually did, these users had no way to view the process as part of their work lives. It was merely another software environment to memorize. Thus, we come to Rule Number One.

\section{RULE NUMBER ONE: LOOK AT PROCESSES}

By looking at work processes, we can bring people into the DAM system by showing them how it fits into what they need to do. Show them how it can make their lives easier! Yes, a good DAM system is a cool application, but the coolest application in the world is going to gather dust if users don't see how it benefits them. They all want to know, "What's in it for me?"

When they do see how the tool fits into their everyday work processes, it becomes something significant, something relevant to them.

\section{WHAT WE DID}

Prior to the tool-selection process, we did a rigorous analysis of the processes that would be affected by a DAM system. What did people do? Where was there room to bring more efficiency to the process? What could we give our users so that they'd be falling all over themselves to use our wonderful new system? This is the time to think from the point of view of a busy Marketing Communication (MC) professional and consider the benefit the DAM system could bring to them.

Let's face it: If you build it, they'll ignore it unless you can show them that it'll do them some good.

We spent a lot of time looking at existing processes, then redesigning those processes for greater efficiency. Our DAM system is part of the new processes, but it's only a part. It isn't the whole thing. We also spent a lot of time and energy on the tool-selection process. If we had chosen something that was hard to use, getting people to want to use it might have been impossible.

We developed "swim lane" charts to look at the workflow, the way an asset moves through the DAM process, not just through the DAM system. Some of these charts are included at the end of this paper. (Please note that we are learning as we go, and these charts will evolve over time.)

- Who does what? What are the roles people assume within the DAM process?

- Who initiates processes?

- Who approves assets?

- Who uploads them?

- Who is responsible for metadata? (Deciding what metadata fields to use, what values are appropriate for each field and who is responsible for ensuring that the metadata is entered for each asset.)

- Who is responsible for the directory structure?

- Where do end users fit in? Who gets access to what assets?

- What kinds of access restrictions are there?

\section{WHAT EXISTED BEFORE}

As with many companies, our DAM process was basically a conglomeration of jury-rigged processes that had grown up over time. There was no real organization and, perhaps as important, no mechanism for sharing things 
across the company or with outside partners. While there were processes that worked fairly well, there was no single standardized process.

\section{THE ANALYSIS}

With no single process or system in place, we opted to look more at what was needed rather than at what existed. We talked with potential users to see what they wanted. In principle, it was simple: easy access, easy searches, easy sharing of assets and tight security. People wanted to be able to find what they need quickly. They want to avoid having to create assets that someone else had already created.

As a company, we want to make work processes more efficient. Creating a system that actually works the way users think it should is a great way to meet these goals.

\section{HOW IT WORKED}

Actually, as of this writing, a better heading might be "how it's working." This is a large company, and we're working on rolling the DAM system and processes out to the entire company, one business unit at a time. That being said, we learn as we go. As mentioned above, my early training plans were more about the "wow" of the DAM tool and omitted most of "what can it do for me?" Our first training session, which focused more on the tool itself, wasn't very effective.

Since then, we've focused on what the DAM process can do for our users. In training sessions, our focus has been on following the life of an asset, from its creation through its final approval for use and, ultimately, the end of its useful life. By showing how our agencies and other vendors can use the tool to deliver their products to us, how the system can help with the review and approval of assets and how we can control access and usage, we've gone from showing the toys to showing how DAM will make users' lives easier. The illustration below depicts a highly simplified version of the life of an asset.

We're basically borrowing on an old adage from the early days of the PC revolution, that computers should work and people should think. Our DAM system does what it should: it takes a lot of the drudgery out of the process. To sell it, we have to show folks how they can use a relatively easy system to eliminate a lot of drudgery.

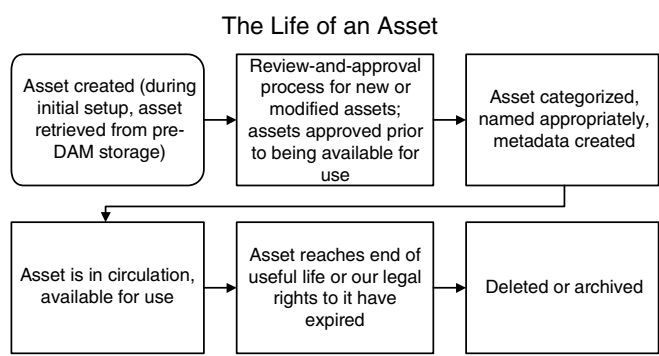

\section{TRAINING IN THE LIFE OF AN ASSET}

We found that using the life of an asset as the guide to our training made a lot more sense from the point of view of the participants. We asked participants to bring one or two assets (images or documents) to the session. We divided the group into teams, with one or two participants playing each of the roles (creator, uploader, owner, super-user). Once they'd tried the tasks involved, we had them switch roles. It doesn't take much time, but it shows how each role works and what the system does to help.

For the last part of the training, we wanted to give each participant a certificate, but we set it up so they could use the custom-publishing feature of the DAM tool to create their own. Each participant put his or her name, the course date and the instructor's name in the appropriate places and produced a PDF. We did the same to award each group with something. Some were the noisiest, the most lively, the fastest, etc. Participants came up with the ideas and used the DAM system to create the certificates.

With these two concepts, allowing them to see how the roles worked and having them use the system to create their own certificates, the participants came to have a sense of ownership for the system. "This is something I can do, something that will do me some good."

\section{REMEMBER THE KISS PRINCIPLE}

The KISS principle ("keep it simple, stupid!" $\mathrm{a} / \mathrm{k} / \mathrm{a}$ "keep it short and simple") is essential when you're trying to get users to adopt the system. Any good DAM setup is a complex, multidimensional system. That being said, when our users go to the DAM tool, they're not interested in whether there's an SQL (structured 
query language) Server database behind it as opposed to Oracle. They may not know - and almost certainly won't care - that there's a database at all. They want to know how to get from Point A (I don't have what I need.) to Point B (I have what I need.) That's their goal, and your goal is to show them how DAM will get them there quickly and easily.

\section{THE BOTTOM LINE: MAKE 'EM WANT IT, OR THEY WON'T BOTHER}

The people who will gain from using the DAM system are, most likely, pretty busy.

They're juggling priorities, trying to get things done. When they're faced with change, they know that it's going to take some time to get used to the new way, and time is something they just don't have. If DAM is presented as part of an overall system that will make their lives easier, that will save them significant time in the long run, then they'll be interested. If they see it as another Program of the Month, they'll dismiss it and move on. If they see it only as a cool toy and don't see how it will make their jobs easier, they'll dismiss it and move on.

Only by helping your user population to see what they'll gain by going through the pain of changing can you win them over and lead them away from their stable — unsatisfactory relationship with whatever you're trying to replace.

\section{SAMPLES OF THE PROCESS}

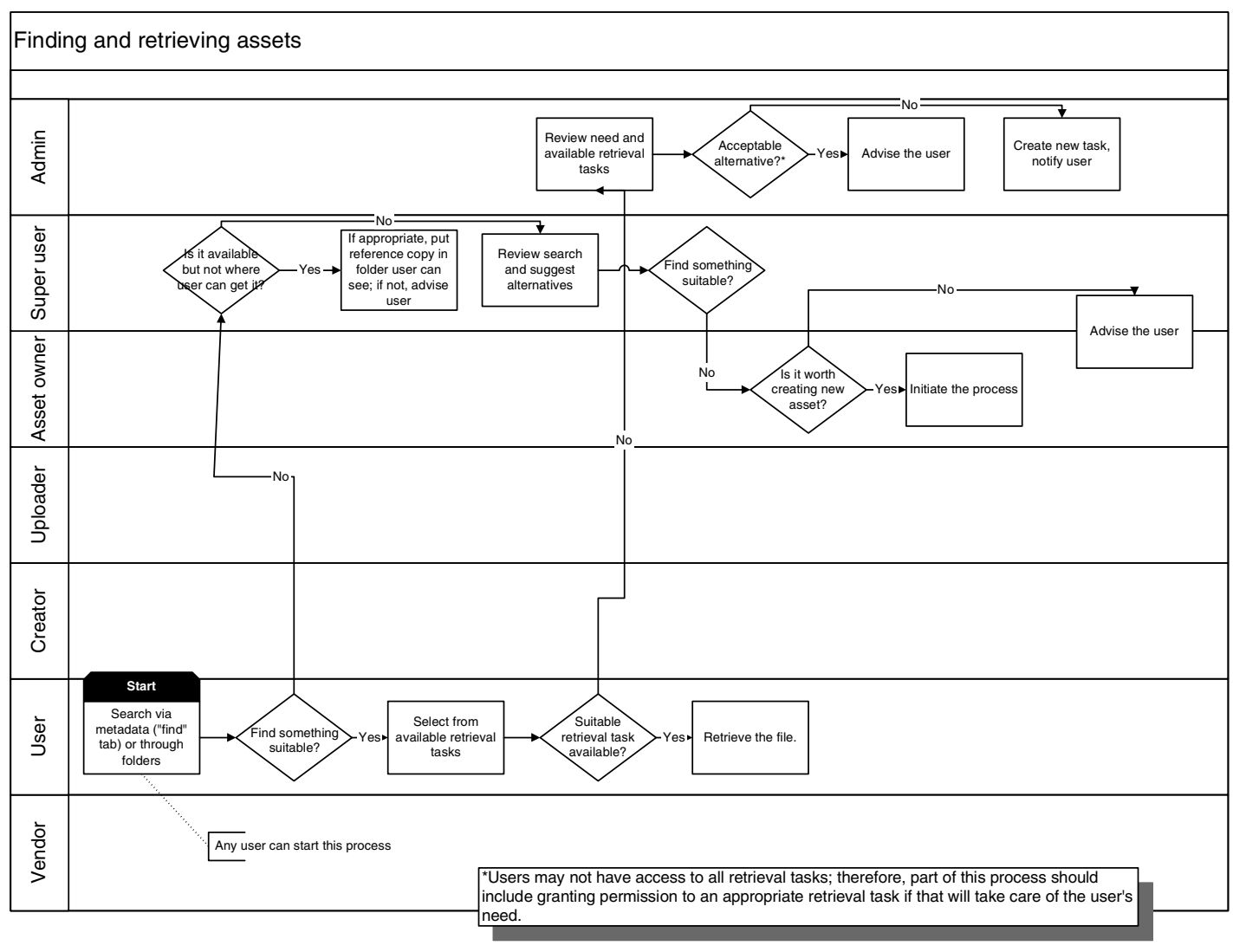




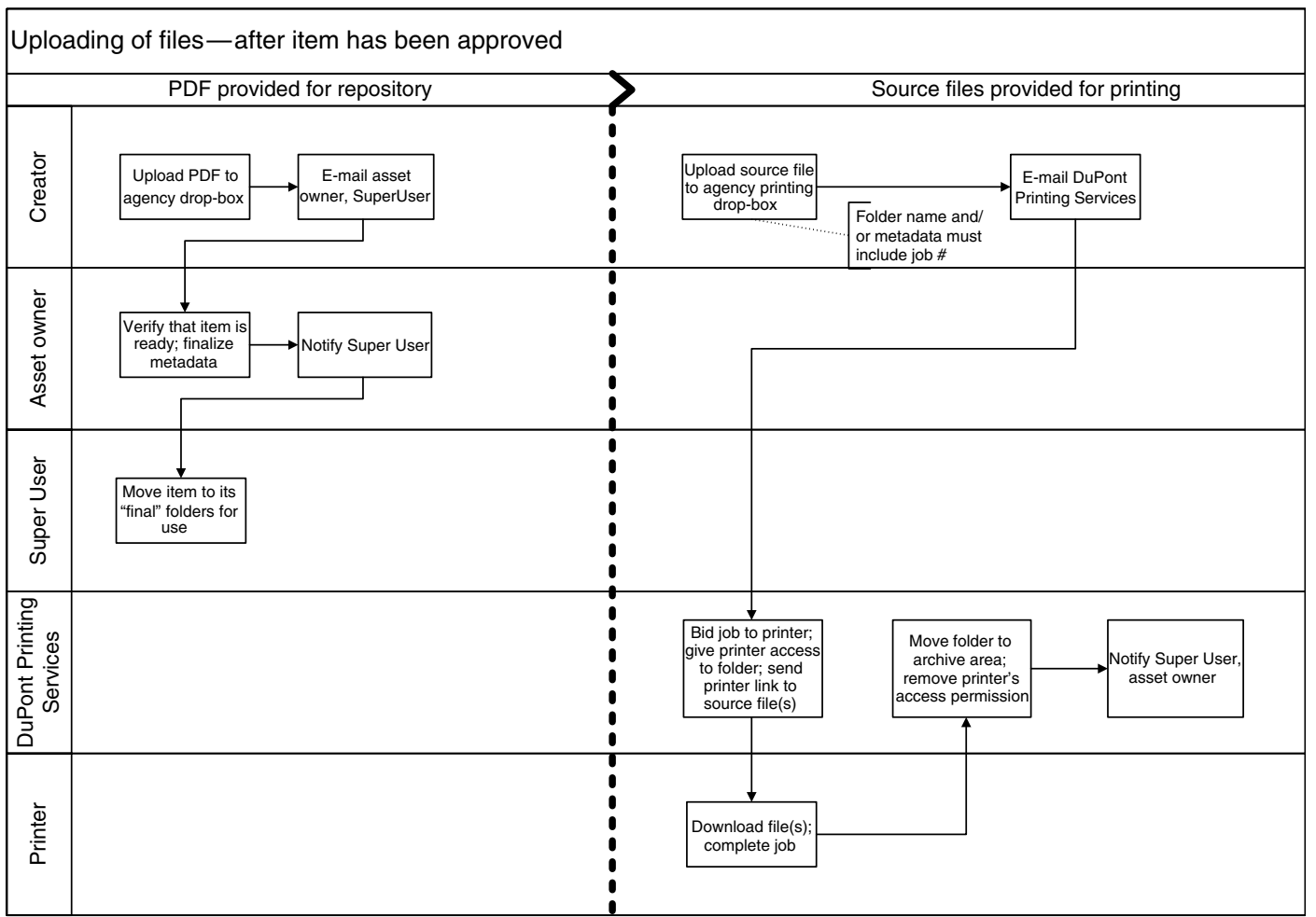

